\title{
Nutritional risk and signs and symptoms of swallowing disorders in hospitalized elderly
}

\author{
Letícia de Carvalho Palhano Travassos ${ }^{1}$ \\ https://orcid.org/0000-0002-3012-2100 \\ Daniela Xavier de Souza ${ }^{2}$ \\ https://orcid.org/0000-0003-1266-1714 \\ Jayne de Freitas Bandeira ${ }^{3}$ \\ https://orcid.org/0000-0002-8066-2201 \\ Darlyane de Souza Barros Rodrigues ${ }^{2}$ \\ https://orcid.org/0000-0001-9112-7653 \\ Ana Karênina de Freitas Jordão do Amaral ${ }^{4,5}$ \\ https://orcid.org/0000-0002-7470-7717 \\ Talita Maria Alves Lopes da Silva ${ }^{6}$ \\ https://orcid.org/0000-0003-2599-3144 \\ Leandro Pernambuco ${ }^{2,4,7}$ \\ https://orcid.org/0000-0001-6246-9769
}

Universidade Federal da Paraíba - UFPB, Hospital Universitário Lauro Wanderley, Empresa Brasileira de Serviços Hospitalares,João Pessoa, Paraíba, Brasil. ${ }^{2}$ Universidade Federal da Paraíba UFPB,Programa Associado de Pósgraduação em Fonoaudiologia (PPgFonUFPB/UFRN), João Pessoa, Paraíba, Brasil.

${ }^{3}$ Universidade Federal da Paraíba - UFPB, Curso de Fonoaudiologia, João Pessoa, Paraíba, Brasil.

Universidade Federal da Paraíba - UFPB, Departamento de Fonoaudiologia, João Pessoa,Parába,Brasil.

${ }^{5}$ Universidade Federal da Paraíba - UFPB Programa de Pós-graduação em Gerontologia, João Pessoa, Paraíba, Brasil.

${ }^{6}$ Universidade Federal da Paraíba - UFPB, Departamento de Nutrição, João Pessoa Paraíba, Brasil.

Universidade Federal da Paraíba - UFPB, Programa de Pós-graduação em Modelos de Decisão e Saúde (PPgMDS), João Pessoa,Paraíba,Brasil.

Project carried out at the Departamento de Fonoaudiologia, Universidade Federal da Parába - UFPB - João Pessoa, Parába, Brazil.

Conflict of interests: Nonexistent

\section{(c) (i)}

Received on: April 23, 2019

Accepted on: October 11, 2019

Corresponding address:

Leandro Pernambuco

Departamento de Fonoaudiologia Cidade Universitária

CEP: 58051-900 - João Pessoa, Paraíba, Brasil

E-mail: leandroape@globo.com

\section{ABSTRACT}

Purpose: to relate nutritional risk and signs and symptoms of swallowing disorders as reported by hospitalized elderly, as well as to correlate the Mini-Nutritional Assessment (MNA) total score with the total number of signs and symptoms.

Methods: a cross-sectional study with a convenience sample of 28 hospitalized patients, mean age of $72.18 \pm 5.92$ years, $15(53.6 \%)$ males. The nutritional risk was evaluated by the MNA total score. Signs and symptoms of alterations in swallowing were investigated by means of an interview with 11 items. The Spearman's correlation coefficient and the Mann-Whitney test were applied. The confidence interval was of $95 \%$.

Results: half the sample reported at least one sign or symptom of alteration in swallowing, with choking being the most frequent (32.1\%). The MNA total score median (19.75) indicated nutritional risk. Elderly who reported choking presented worse performance in the MNA $(p=0.05)$. There was no correlation between the MNA total score and the total number of signs and symptoms of alterations in swallowing.

Conclusion: nutritional risk was higher in hospitalized elderly with complaint of choking, but no correlation was found between the total number of signs and symptoms of alterations in swallowing and the MNA total score in this population.

Keywords: Swallowing Disorders; Swallowing; Elderly; Aging; Malnutrition; Hospital 


\section{INTRODUCTION}

Aging is a dynamic and progressive process, common to all living beings, and it is influenced by multiple factors (biological, psychological, economic, social, cultural, among others) ${ }^{1}$ which, if altered, may compromise the elderly's functional independence, health conditions and, consequently, quality of life ${ }^{1,2}$.

In the elderly, the decrease in functional capacity, the aging process and the load of chronic affections result in a greater need of both out- and inpatient health services $^{2}$. Hospitalization is a complex and peculiar event that removes the person from their environment and family and social life, in addition to being a risk factor for functional decline in elderly people, due to the loss of dependence and autonomy ${ }^{3}$. Many factors may influence this result, including the nutritional status ${ }^{4}$.

The nutritional status brings impact to the physical and emotional condition of the elderly, as this is the population of greater risk for malnutrition ${ }^{5,6}$ as a consequence of the reduction in food intake, alterations in taste, presence of debilitating diseases, social isolation, alterations in health condition, economic limitations, and multiple hospitalizations, which may increase the time and cost of hospital stay?.

One of the factors that might cause or worsen the nutritional decline in elderly is oropharyngeal dysphagia, a condition that refers to a disorder in the preparatory, oral and/or pharyngeal stages of swallowing, whose signs and symptoms include choking, coughing, sensation of food stuck in the throat, weight loss, among others ${ }^{8}$. The progression of oropharyngeal dysphagia may compromise the person's clinical, nutritional and/or social aspects, including outcomes such as malnutrition, dehydration and respiratory complications, even leading to death ${ }^{8,9}$. Thus, it is important that patients in nutritional risk and with signs and symptoms of alterations in swallowing be early detected, in order to achieve a better prognosis and immediate intervention, especially in hospitalized elderly ${ }^{10-12}$.

From the theoretical and biological point of view, it is assumed that nutritional status and oropharyngeal dysphagia are linked events ${ }^{13,14}$. However, there remains to be found whether in hospitalized elderly the nutritional risk is related to signs and symptoms of alterations in swallowing. Hence, the objective of this study was to investigate if there is a relation between nutritional risk and signs and symptoms of swallowing disorders reported by hospitalized elderly, as well as to correlate the total score of instruments used to investigate these events.

\section{METHODS}

This is an observational, analytical, documental, cross-sectional study, carried out at the Hospital Universitário Lauro Wanderley (HULW/EBSERH/ UFPB). It was approved by the Human Research Ethics Committee of the HULW/EBSERH/UFPB, and by the Human Research Ethics Committee of the abovementioned hospital, as stated in the evaluation report 2.653.250/18 and in the Certificate of Presentation for Ethical Consideration (CAAE) 88742118.7.0000.5183, in compliance with the Declaration of Helsinki and with the Resolution 466/2012, of the National Health Council - Conselho Nacional de Saúde (CNS). All the participants voluntarily signed an Informed Consent Form.

The research was carried out with hospitalized elderly aged 60 years or over, of both genders, regardless of clinical diagnosis and type of treatment. Patients were excluded who had serious cognitive impairment according to the result of the Short Portable Mental Status Questionnaire (SPMSQ) ${ }^{15}$; elderly with difficulty to understand and perform simple orders; with reduced awareness level; with severe hearing loss without the use of well-adapted electronic device; totally or partially laryngectomized; and, tracheostomized. The exclusion criteria were determined in accordance with medical record consultation, patient's self-report, caregiver's report or evaluator's perception.

The research was made on a nonprobability convenience sample. Those who met the eligibility criteria were approached by one of the researchers, who explained the objectives of the study and presented the ICF, which was voluntarily signed by those who agreed to participate.

Thus, the sample was composed of 28 elderly, aged 60 years or over (meanage $72.18 \pm 5.92$ years); 15 $(53.6 \%)$ were male. In greater proportion were the cases of low schooling ( $n=15 ; 53.6 \%)$, partnerless ( $=15 ; 53.6 \%)$, with children $(n=26 ; 92.9 \%)$, retired $(n$ $=21 ; 75 \%)$, and with low income $(n=22 ; 78.6 \%)$. The time of hospital stay varied from one to 48 days, and four (14.3\%) elderly made use of alternative feeding route.

The sociodemographic and clinical characteristics were obtained through interviewing the patient or consulting the medical report. The main variables of the study had already been collected in the hospital's speech-language-hearing and nutrition routine service; these data, then, were obtained exclusively from the medical reports. 
The nutritional risk was evaluated through the Mini-Nutritional Assessment $(\mathrm{MNA})^{16}$ in its Brazilian Portuguese version ${ }^{17}$. The MNA is an instrument specifically used for the identification of risk of malnutrition. It is a protocol composed of 17 items, subdivided in four domains: anthropometry, dietary assessment, general evaluation, and self-perception. The items may score from 0 to 3 points, and the final score may reach up to 30 points. The person may be classified as malnourished (>17 points), at nutritional risk (between 17 and 23.5 points) or well-nourished ( $\leq 24$ points).

To investigate signs and symptoms of alterations in swallowing reported by the hospitalized elderly, an interview instrument was used, which is composed of 11 dichotomous items (yes/no), approaching the following aspects: need of swallowing many times the food (multiple swallowing), effort to swallow, avoid eating some food for finding it difficult to swallow, notice the nose run after eating (runny nose), throat clearing after eating, change in voice after swallowing, choking when swallowing, history of pneumonia or weight loss, pain when swallowing (odynophagia), and fatigue after eating. These 11 items have been determined based on the 17 questions of a preliminary version of the "Screening for Dysphagia in the Elderly" (RADI, its Portuguese acronym $)^{18}$, an instrument whose development counted with the participation of two researchers of this study. The RADI version used as a basis for this research was the one presented after having obtained the evidences of validity based on the content and response processes ${ }^{18}$. Although the validation process for the RADI hadn't been concluded at the time of the collection, it was considered, from the psychometric point of view, the most consisted instrument in Brazilian Portuguese at that moment. The selection of the 11 items was made by the authors of this study after pondering upon the relevance of each item for the population of hospitalized elderly. For the purpose of analysis, the total number of signs and symptoms reported was calculated (0 to 11 ), as well as the distribution of frequency of each item separately.

The quantitative variables were analyzed in accordance with measures of central tendency (mean and median) and dispersion (standard deviation and interquartile range). The categorical variables were described in relation to their absolute and relative frequency. The correlation between the MNA score and the total number of reported signs and symptoms was analyzed through Spearman's correlation coefficients. For the analysis of distribution of MNA score averages according with the presence or absence of each sign and symptom, the nonparametric Mann-Whitney test was used. The confidence interval was of $95 \%$.

\section{RESULTS}

In Table 1, it is observed that the total number of signs and symptoms of alterations in swallowing oscillated between 0 and 7 , and that half of the sample reported at least one symptom. The median of the MNA score indicated that the hospitalized elderly were found to be at nutritional risk. According to the MNA classification, seven (25\%) elderly were malnourished, and 19 $(67.9 \%)$ at risk of malnutrition, whereas only two $(7.1 \%)$ were classified as well-nourished.

Table 1. Measures of central tendency and dispersion of the total number of signs and symptoms of alterations in swallowing and of the Mini-Nutritional Assessment total score

\begin{tabular}{ccccccc}
\hline & mean & $\begin{array}{c}\text { standard } \\
\text { deviation }\end{array}$ & minimum & maximum & median & Q25-Q75 \\
\hline $\begin{array}{c}\text { Total number } \\
\text { of signs and } \\
\text { symptoms of } \\
\begin{array}{c}\text { alterations in } \\
\text { swallowing } \\
\text { MAN }\end{array}\end{array}$ & 1.86 & 2.18 & 0 & 7 & & \\
\hline
\end{tabular}

Legend: MNA = Mini-Nutritional Assessment; Q25-Q75 = interquartile range. 
According to Figure 1, choking after swallowing (32.1\%) was the most frequently reported symptom, followed by throat clearing after swallowing (21.4\%), and avoiding eating because of difficulty to swallow (21.4\%).
There was no significant correlation between MNA total score and the total number of signs and symptoms of alterations in swallowing (rho $=-0.112$; $p=0.57$ ) (Figure 2), i.e., these variables have shown to be independent in hospitalized elderly.

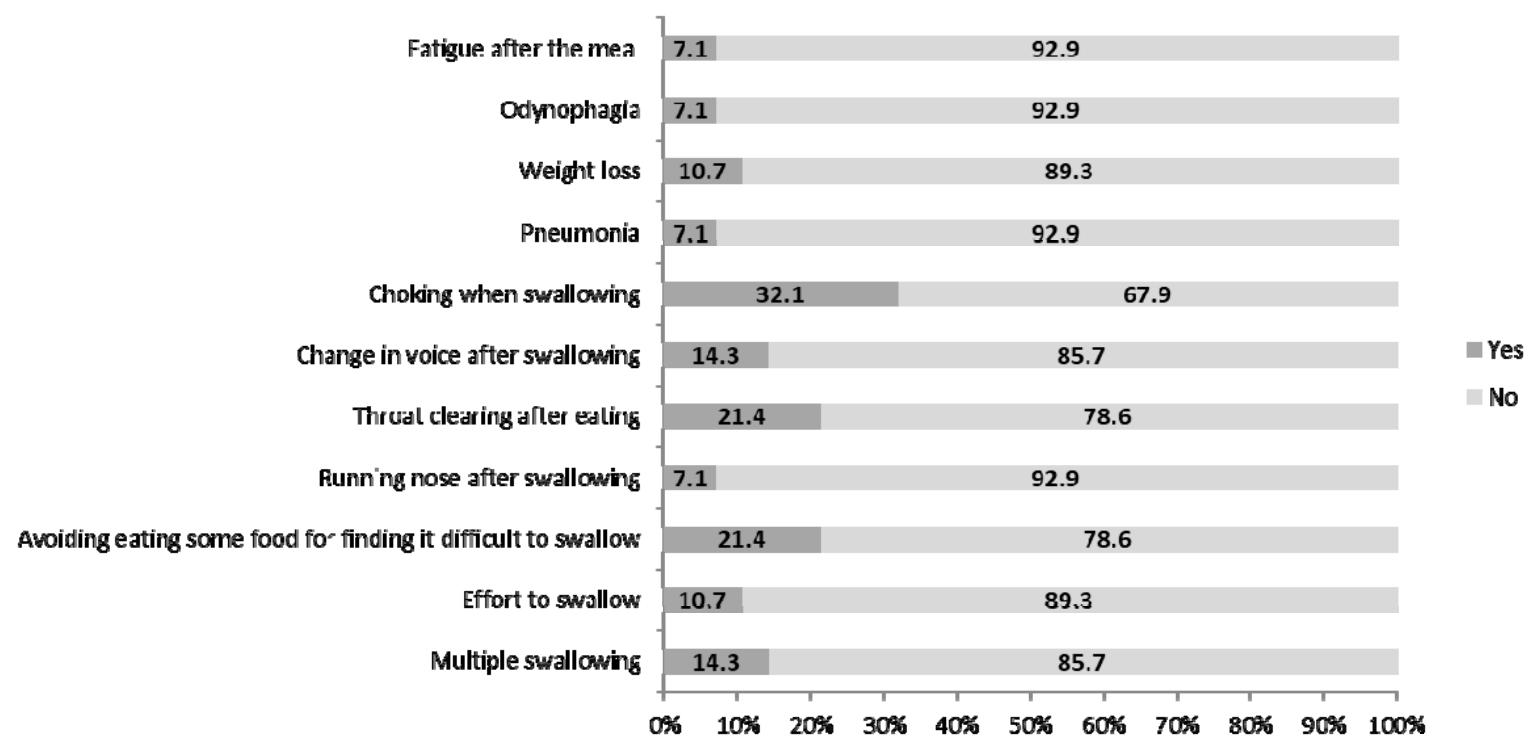

Figure 1. Percentage distribution of the signs and symptoms of alterations in swallowing reported by hospitalized elderly

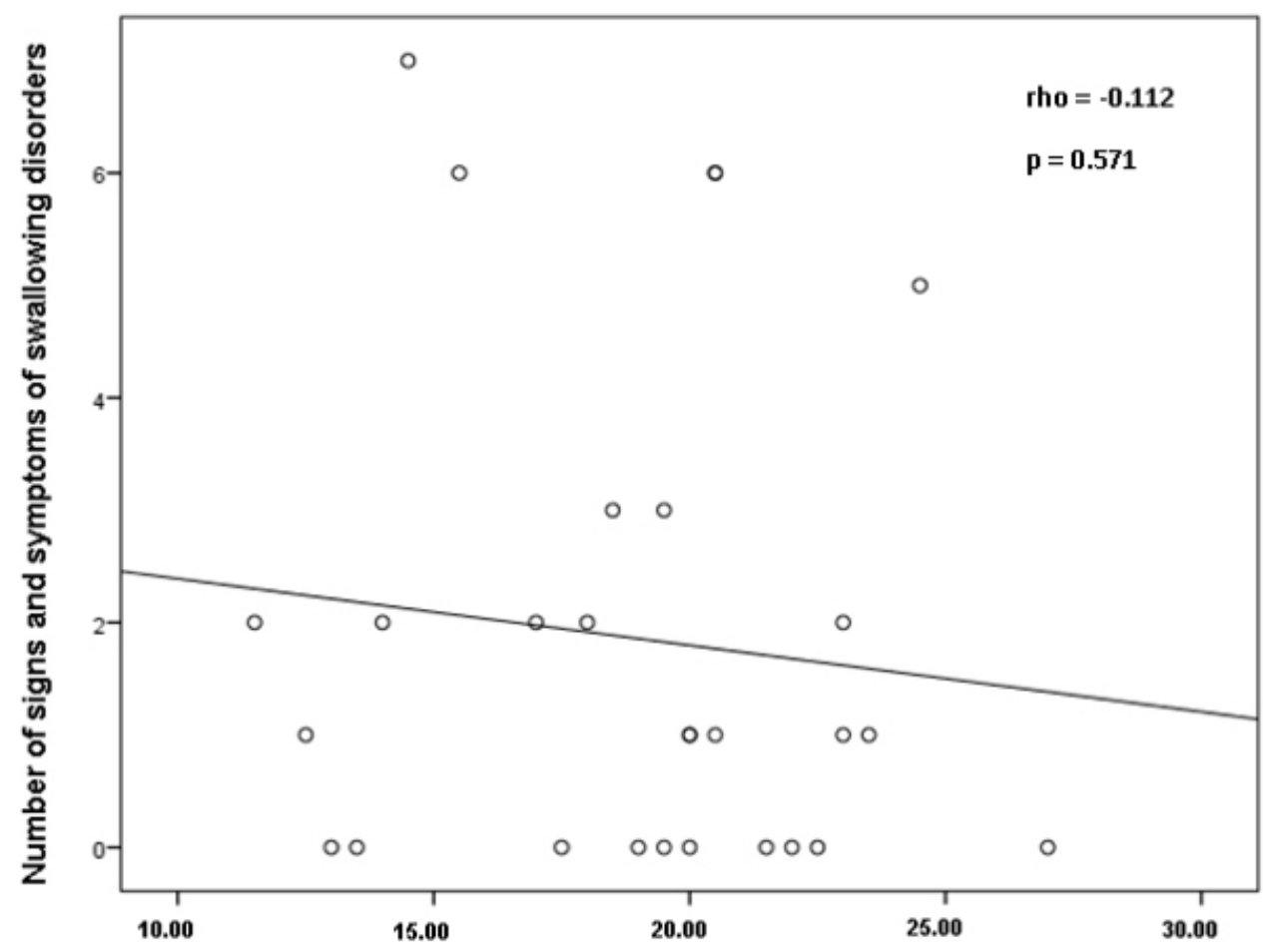

Figure 2. Correlation between the Mini-Nutritional Assessment (MNA) total score and the total number of signs and symptoms of swallowing disorders 
In Table 2, it is possible to visualize the relation between MNA total score and each item of self-reported alteration in swallowing. In hospitalized elderly with complaint of choking, the mean of the MNA average total score was lower in relation to those without complaint of choking; this was the only statistically significant relation found.

Table 2. Relationship between signs and symptoms of swallowing disorders and nutritional risk, represented by Mini-Nutritional Assessment (MNA) total score in hospitalized elderly

\begin{tabular}{|c|c|c|c|}
\hline \multirow{2}{*}{ Signs and symptoms of swallowing disorders } & \multicolumn{2}{|c|}{ MNA* total score (nutritional risk) } & \multirow{2}{*}{$P$ value } \\
\hline & Mean & standard deviation & \\
\hline \multicolumn{4}{|l|}{ Multiple swallowing } \\
\hline Yes & 20.25 & 3.68 & 0.35 \\
\hline No & 18.79 & 3.98 & \\
\hline \multicolumn{4}{|l|}{ Effort to swallow } \\
\hline Yes & 19.83 & 5.03 & 0.52 \\
\hline No & 18.90 & 3.87 & \\
\hline \multicolumn{4}{|l|}{ Avoiding eating for swallowing difficulty } \\
\hline Yes & 20.41 & 3.20 & 0.25 \\
\hline No & 18.61 & 4.06 & \\
\hline \multicolumn{4}{|l|}{ Running nose after swallowing } \\
\hline Yes & 20.00 & 4.24 & 0.75 \\
\hline No & 18.92 & 3.96 & \\
\hline \multicolumn{4}{|l|}{ Throat clearing after swallowing } \\
\hline Yes & 18.08 & 2.70 & 0.46 \\
\hline No & 19.25 & 4.20 & \\
\hline \multicolumn{4}{|l|}{ Vocal alteration after swallowing } \\
\hline Yes & 18.00 & 4.35 & 0.71 \\
\hline No & 19.16 & 3.91 & \\
\hline \multicolumn{4}{|l|}{ Choking after swallowing } \\
\hline Yes & 16.55 & 3.97 & $0.05^{\star *}$ \\
\hline No & 20.15 & 3.39 & \\
\hline \multicolumn{4}{|l|}{ Pneumonia } \\
\hline Yes & 19.00 & 6.36 & 0.78 \\
\hline No & 19.00 & 3.86 & \\
\hline \multicolumn{4}{|l|}{ Weight loss } \\
\hline Yes & 19.50 & 5.00 & 0.82 \\
\hline No & 18.94 & 3.88 & \\
\hline \multicolumn{4}{|l|}{ Odynophagia } \\
\hline Yes & 22.50 & 2.82 & 0.12 \\
\hline No & 18.73 & 3.89 & \\
\hline \multicolumn{4}{|l|}{ Fatigue after the meal } \\
\hline Yes & 16.75 & 1.76 & 0.28 \\
\hline No & 19.17 & 3.99 & \\
\hline
\end{tabular}

Source: own source

Legend: MNA $=$ Mini-Nutritional Assessment; ${ }^{*} p \leq 0.05$ (Mann-Whitney Test). 


\section{DISCUSSION}

This study has shown that hospitalized elderly with complaint of choking have worse scores in the nutritional risk assessment. Nevertheless, though swallowing-related complaint and nutritional risk are found in the hospitalized elderly population, the MNA total score and the total number of signs and symptoms of alterations in swallowing do not correlate.

The average amount of signs and symptoms of alterations in swallowing was expected to be higher, as in aging multiple physiological modifications take place, which diminish the efficacy of the respiratory tract protection mechanisms and increase the possibilities of alterations in swallowing ${ }^{1}$. Furthermore, the elderly are more prone for primary diseases to occur bringing dysphagia as a consequence ${ }^{1,19,20}$.

However, such result being short of the expected may be justified by the elderly not valuing symptoms of this nature, as they frequently believe that the alterations in swallowing are common to aging ${ }^{20}$, or because other health conditions bother them more often and more intensely, especially during hospital stay. Moreover, most of the elderly seem to manage to adapt to the changes that come with aging ${ }^{21}$, and it may happen with swallowing. Therefore, it is believed that such situations may have interfered with the self-report regarding swallowing difficulties.

Concerning nutritional risk, it is known that the assessment of nutritional status in the hospital context is fundamental, due to the consequences that malnutrition can cause, such as further chances of infections, clinical complications, reduced immunological function, lengthening of hospital stay, and increase in hospital costs, besides the greater risk of mortality ${ }^{13}$. Even though the malnutrition rate in hospitalized elderly is known to be high and to have the possibility of impairing the patient's clinical condition ${ }^{22}$, attention is called in this study to almost $93 \%$ of the elderly being either malnourished or at risk of malnutrition, according to the MNA. This result is higher than other surveys conducted in Brazil, in which these proportions oscillated between $48 \%$ and $68 \%{ }^{11,12,23}$.

The most reported oropharyngeal dysphagia symptom by the sample of this investigation was choking after swallowing, a result that equates to those of other studies with hospitalized ${ }^{24,25}$ and non-hospitalized ${ }^{26-28}$ elderly. Choking occurs due to the entrance of saliva, food or a body foreign to the larynx, causing the sensation of suffocation, with local pain and coughing reflex ${ }^{29}$. In elderly, the physiological or pathological modifications of the sensorimotor system make them more prone to episodes of choking, and, though they report suffering with this symptom, they do not see it as something avoidable or controllable ${ }^{28}$. Nonetheless, it is known that the limitations imposed by choking can result in worsened quality of life and in enhanced morbimortality ${ }^{30}$.

Furthermore, the presence of oropharyngeal dysphagia is known to have an impact on hospital management, as it increases both the cost with healthcare and the length of hospital stay ${ }^{31}$. Thus, it is presumed that investigating the occurrence of choking in hospitalized elderly favors the early identification of the population with oropharyngeal dysphagia in that environment, which enables the problems with feeding and swallowing to be monitored more precisely, in order to minimize hospital expenses and precociously determine the speech-language-hearing, nutritional and interprofessional procedures ${ }^{14}$.

In addition to being the most reported symptom, choking was the only one of the items whose relation to MNA total score was significant. This result points to complaint of choking as possibly one of the aspects capable of better distinguishing who is and who is not at nutritional risk; such hypothesis may be investigated by future studies with adequate methodological design for this end.

There was no significant correlation between MNA total score and the total number of signs and symptoms of alterations in swallowing; this result dis not correspond to the initial hypothesis of the authors of this study, in which it was supposed that there would be a negative strong correlation between these two outcomes. It is possible that this happened as a consequence of the small representativeness of individuals with a more expressive amount of swallowing-related complaints, as well as of elderly without alterations in nutritional status. This characteristic may have contributed to the occurrence of type II error.

It may also be considered that the MNA contemplates elements of assessment, whereas the survey of signs and symptoms of alterations in swallowing was based only in self-report. The distinct nature of the two instruments may have interfered with the results. It is possible that instruments considering elements of clinical assessment of swallowing will have more correlation with the result of the MNA. Yet, the lack of correlation between these two outcomes is important to confirm that they evaluate different constructs. Hence, 
they are complementary and should both be applied in hospital routine.

This study has presented some limitations. The sample's reduced size and restricted variability may have interfered with the results and confidence intervals. No validated instrument was used to investigate the signs and symptoms of alterations in swallowing, because, at the time of collection, no instruments with these characteristics were available in Brazilian Portuguese. Even though it was not the objective of this study, it is important to highlight that neither clinical nor instrumental assessment data regarding swallowing were collected which could have confirmed the diagnosis of oropharyngeal dysphagia, as well as no data on the evolution of the nutritional status were obtained. Future studies should better control these aspects.

It is emphasized that the results have shown that, in the hospital environment, the elderly have a sharp nutritional decline and report swallowing-related complaints, especially choking, whose presence is related to nutritional risk. In spite of the absence of correlation between the outcomes of the instruments used in this study, they provide complementary information that must be investigated in the hospital routine. Such situations call for attention and care because of the consequences malnutrition and alterations in swallowing may have on the patient's general clinical condition, and the increase in expenses which these conditions represent for the health services.

\section{CONCLUSIONS}

A relationship between nutritional risk and selfreported choking in hospitalized elderly was found. However, the correlation between MNA total score and the total number of signs and symptoms of alterations in swallowing was not seen in this population.

\section{ACKNOWLEDGEMENT}

Gratitude is extended to the Programa Institucional de Bolsas de Iniciação Científica do Conselho Nacional de Desenvolvimento Científico e Tecnológico (CNPq - PIBIC/CNPq), for the scholarship granted to Letícia de Carvalho Palhano Travassos; and to the Programa Institucional de Voluntários de Iniciação Científica (PIVIC) of the UFPB, for awarding Daniela Xavier de Souza and Jayne de Freitas Bandeira.

\section{REFERENCES}

1. Wirth R, Dziewas R, Beck AM, Clavé P, Hamdy $\mathrm{S}$, Heppner $\mathrm{HJ}$ et al. Oropharyngeal dysphagia in older persons - from pathophysiology to adequate intervention: a review and summary of an international expert meeting. Clin Interv Aging. 2016;11:189-208.

2. Cunha FCM, Cintra MTG, Cunha LCM, Giacomin $\mathrm{KC}$, Couto $\mathrm{EAB}$. Fatores que predispõem ao declínio funcional em idosos hospitalizados. Rev. bras. geriatr. gerontol. 2009;12(3):475-87.

3. Pereira BEE, Biene A, Rassy CS, Nascimento FSES. Funcionalidade global de idosos hospitalizados. Rev. bras. geriatr. gerontol. 2014;17(1):165-76.

4. Silva HGV. Evaluación nutricional asociada com la estancia hospitalaria. Nutr. hosp. 2012;(2):542-7.

5. Azevedo LC, Fenilli M, Farias MB, Breitkopf $T$, Silva AA, Esmeraldino R. Principais fatores da mini avaliação nutricional associados a alterações nutricionais de idosos hospitalizados. ACM Arq. Catarin. Med. 2007;36(3):7-14.

6. Silva JL, Marques APO, Leal MCC, Alencar DL, Melo EMA. Fatores associados à desnutrição em idosos institucionalizados. Rev. bras. geriatr. gerontol. 2015;18(2):443-51.

7. Soares ALG, Mussoi TD. Mini nutritional assessment to determine nutritional risk and malnutrition in elderly hospitalized. Rev. bras. nutr. clin. 2014;2(29):105-10.

8. Rommel N, Hamdy S. Oropharyngeal dysphagia: manifestations and diagnosis. Nat. Rev. Gastroenterol. Hepatol. 2015;13(1):49-59.

9. Wakabayashi H. Presbyphagia and sarcopenic dysphagia: association between aging, sarcopenia, and deglutition disorders. J Frailty Aging. 2014;3(2):97-103.

10. Raslan M, Gonzalez MC, Dias MCG, Paes-Barbosa FC, Cecconello I, Waitzberg DL. Aplicabilidade dos métodos de triagem nutricional no paciente hospitalizado. Rev. Nutr. 2008;21(5):553-61.

11. Soares ALG, Mussoi TD. Mini nutritional assessment to determine nutritional risk and malnutrition in elderly hospitalized. Rev Bras Nutr Clin. 2014;29(2):105-10.

12. Dalpiaz JS, Bertoni VM, Alves ALS, Bertol D. Nutritional status and its evolution during hospitalization in elderly patients. Rev. Bras Nutr Clin. 2015;30(1):34-8.

13. Andrade PA, Santos CA, Firmino HH, Rosa COB. Importância do rastreamento de disfagia e da 
avaliação nutricional em pacientes hospitalizados. Einstein. 2018;16(2):eAO4189.

14. Bomfim FMS, Chiari BM, Roque FP. Factors associated to suggestive signs of oropharyngeal dysphagia in institutionalized elderly women. CoDAS. 2013;25(2):154-63.

15. Pfeiffer E. A short portable mental status questionnaire for the assessment of organic brain deficit in elderly patients. J Am Geriatr Soc. 1975;23(10):433-41.

16. Guigoz Y, Vellas B, Garry PJ. Mini Nutritional Assessment: a practical assessment tool for grading the nutritional state of elderly patients. Fact. Res. Interv. Ger. 1994;2(suppl.):15-59.

17. Sociedade Brasileira de Geriatria e Gerontologia. I Consenso Brasileiro de Nutrição e Disfagia em Idosos Hospitalizados. Barueri: Minha Editora; 2011.

18. Magalhaes Junior HV, Pernambuco LA, Cavalcanti RVA, Lima KC. Screening for Deglutition Disorders in Older People (RADI): validity evidence based on test content and response process. ESSD 2014 Congress Abstracts. Dysphagia. 2015;30(2):253.

19. Turley R, Cohen S. Impact of voice and swallowing problems in the elderly. Otolaryngol Head Neck Surg. 2009;140(1):33-6.

20. Faria KCF, Pessoa ACN, Araújo LI, Paiva MLF. The profile of a patient receiving speech-language therapy assistance at a school hospital emergency unit. Audiol., Commun. Res. 2013;18(4):308-13.

21. Tanure CCM, Pinheiro BJ, Paixão AJ, Rodrigues MA. A deglutição no processo normal de envelhecimento. Rev. CEFAC. 2005;7(2):171-7.

22. Panissa CO, Vassimon HS. Risco de desnutrição de idosos hospitalizados: avaliando ingestão alimentar e antropometria. Demetra. 2012;7(1):13-22.

23. Sousa APG, Gallello DC, Silva ALND, Carreira MC, Damasceno NRT. Triagem nutricional utilizando a Mini Avaliação Nutricional versão reduzida: aplicabilidade e desafios. Geriatr. Geronto. Aging. 2015;9(2):49-53.

24. Nogueira SCJ, Carvalho APC, Melo CB, Morais EPG, Chiari BM, Gonçalves MIR. Profile of patients using alternative feeding route in a general hospital. Rev. CEFAC. 2013;15(1):94-104.

25. Gonçalves MLV, Broglio GAF, Lozano AC, Lamari NM. Perfil dos idosos usuários de via alternativa de alimentação reinternados em hospital público. RBCEH. 2015;12(1):20-7.
26. de Lima Alvarenga EH, Dall'Oglio GP, Murano EZ, Abrahão M. Continuum theory: presbyphagia to dysphagia? Functional assessment of swallowing in the elderly. Eur Arch Otorhinolaryngol. 2018;275(2):443-9.

27. Mourão LF, Xavier DAN, Neri AL, Luchesi KF. Association study between natural chronic diseases of aging and swallowing changes referred by community elderly. Audiol., Commun. Res. 2016;21:e1657.

28. Rozenfeld M, Friedman S. A percepção subjetiva do engasgo em pessoas idosas. Rev. Bra. Ciên. Env. Hum. 2005;2(2):47-56.

29. Bigal A, Harumi D, Luz M, Luccia G, Bilton T. Disfagia do idoso: estudo videofluoroscópico de idosos com e sem doença de Parkinson. Distúrb. Comun. 2007;19(2):213-23.

30. Kramarow E, Warner M, Chen LH. Food-related choking deaths among the elderly. Inj Prev. 2014;20(3):200-3.

31. Attrill S, White S, Murray J, Hammond S, Doeltgen S. Impact of oropharyngeal dysphagia on healthcare cost and length of stay in hospital: a systematic review. BMC Health Serv Res. 2018;18(1):594. 